\title{
PRIORITIZING SUITABLE LOCATIONS OF BIKE SHARING STATION BY USING THE ANALYTIC HIERARCHY PROCESS (AHP)
}

\author{
Tharathorn Kanjanakorn \\ School of Civil Engineering and Technology \\ Sirindhorn International Institute of Technology \\ Thammasat University, Rangsit Campus \\ Pathum Thani, THAILAND \\ E-mail: road ce@hotmail.com \\ Mongkut Piantanakulchai* \\ School of Civil Engineering and Technology \\ Sirindhorn International Institute of Technology \\ Thammasat University, Rangsit Campus \\ Pathum Thani, THAILAND \\ E-mail: mongkutp@gmail.com
}

\begin{abstract}
Presently several cities consider Bike Sharing System (BSS) as an alternative mode of travel in urbanized areas. Recently Bangkok Metropolitan Administration (BMA) established BSS in the central business district (CBD) of Bangkok, aiming at providing the service as a supplementary feeder mode of mass transit. Pick-up and drop-off bike sharing stations are established near mass transit stations and nearby destinations. In this study, the Analytic Hierarchy Process (AHP) is applied to rank suitable locations of bike sharing station by considering factors such as types of land, amount of available space, accessibility to main bike route and walkability to destinations. AHP questionnaires were distributed to BMA's experts in order to reveal relative preferences of aforementioned factors. Group decision is obtained by using geometric mean method. The result of study reveals that experts gave priorities to accessibility to main bike route, walkability to destinations, amount of available space and the types of land, respectively. Finally, a hypothetical case study is used to illustrate the application of AHP to rank suitable locations of bike sharing station.
\end{abstract}

Keywords: Location Analysis, Bike Sharing System, Non-Motorized Transportation, Analytic Hierarchy Process (AHP)

\section{Introduction}

Bangkok, Thailand's center of economic and social activities, is facing with traffic congestion problem due to increasing in number of private motor vehicles and insufficient provision of public transportation services. Relevant agencies have set strategies to alleviate the problem by encouraging people to use public transport and non-motorized transport. Mass transit systems such as elevated railway and subway have been successfully implemented in Bangkok during the past decades (Traffic and Transport Department, 2011). To complement the service of mass transit system, bike sharing system is aimed at serving as the feeder system to mass transit. Bike sharing system has been implemented in many countries such as France, Greece, United Kingdom, United States, Australia, China and Japan. Recently, Bangkok

\footnotetext{
${ }^{*}$ Corresponding author
} 
Metropolitan Administration (BMA) established BSS in the central business district (CBD) of Bangkok, aiming at providing the service as a supplementary feeder mode of mass transit (Figure 1). Bike sharing system usually offers its service in urbanized areas. In some cases such as a university campus, bicycles are only designated to be used within certain boundaries. Users are expected to leave the bike unlocked in public areas once they reach their destination. In urbanized areas, the bike sharing network is larger and the planning is more complicated. Finding suitable locations of pick-up and drop-off stations is one of important tasks in planning successful bike sharing system in a city. As a feeder system to mass transit system the bike sharing's pick-up and drop-off stations are usually located near the mass transit stations and travel destinations such as office buildings, shopping malls, etc. The selection of locations of bike stations near mass transit stations is usually limited mainly to availability of space near mass transit stations. On the other hand, the selection of suitable location near travel destinations is subjected to many considerations. Therefore, the method of prioritizing suitable locations for bike sharing stations near travel destinations is necessary. In this study, the Analytic Hierarchy Process (AHP) is applied to rank potential locations of bike sharing stations.

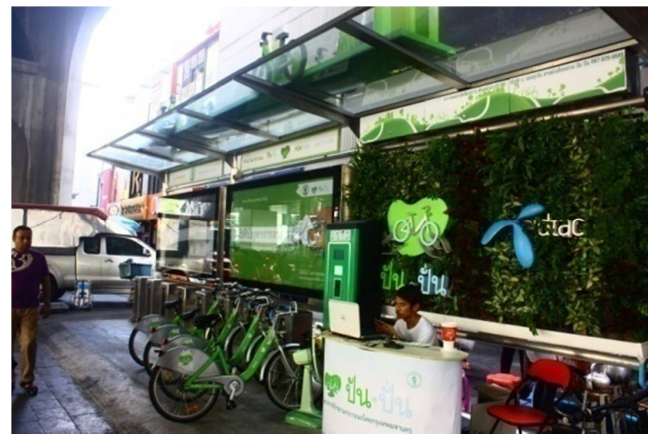

a) Bike Sharing Station at Siam Square

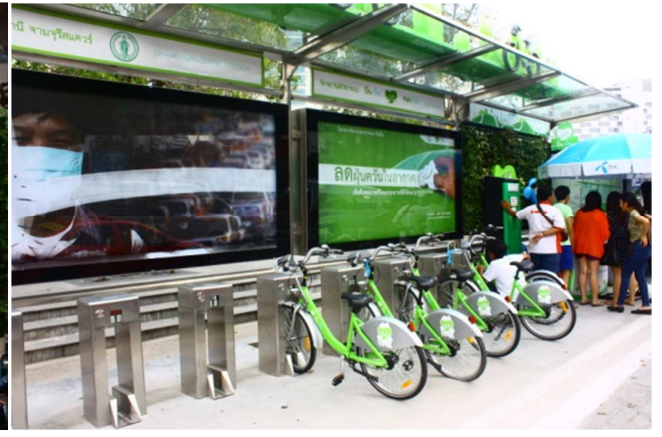

b) Bike Sharing Station at Chamchuri Square

Figure 1. Bike Sharing Stations near Mass Transit Stations in Bangkok

\section{Methodology}

\subsection{Bike Sharing Network}

In this study, the bike sharing network was adopted from Lin and Yang (2011). The bike sharing network consists of 4 types of nodes which are origins (mass transit stations), bike sharing pick-up stations, bike sharing drop-off stations, and destinations (Figure 2). In Lin and Yang (2011) the network was used in the cost minimization model to determine an adequate number and location of bike stations and suitable bike paths which connect stations. In this study, we focused at the specific part of the bike sharing network, between drop-off stations and destinations. The study area of bike sharing system in the CBD of Bangkok is subdivided into small traffic analysis zones (TAZs). Each zone is approximately $200-300$ meters long and 200 - 300 meters wide. There are normally suitable locations of drop-off stations in each zone. In this study, we proposed to use AHP to rank potential drop-off stations in each zone. 
Kanjanakorn T., Piantanakulchai M./ Prioritizing Suitable Locations of Bike Sharing Station by Using the Analytic Hierarchy Process (AHP)

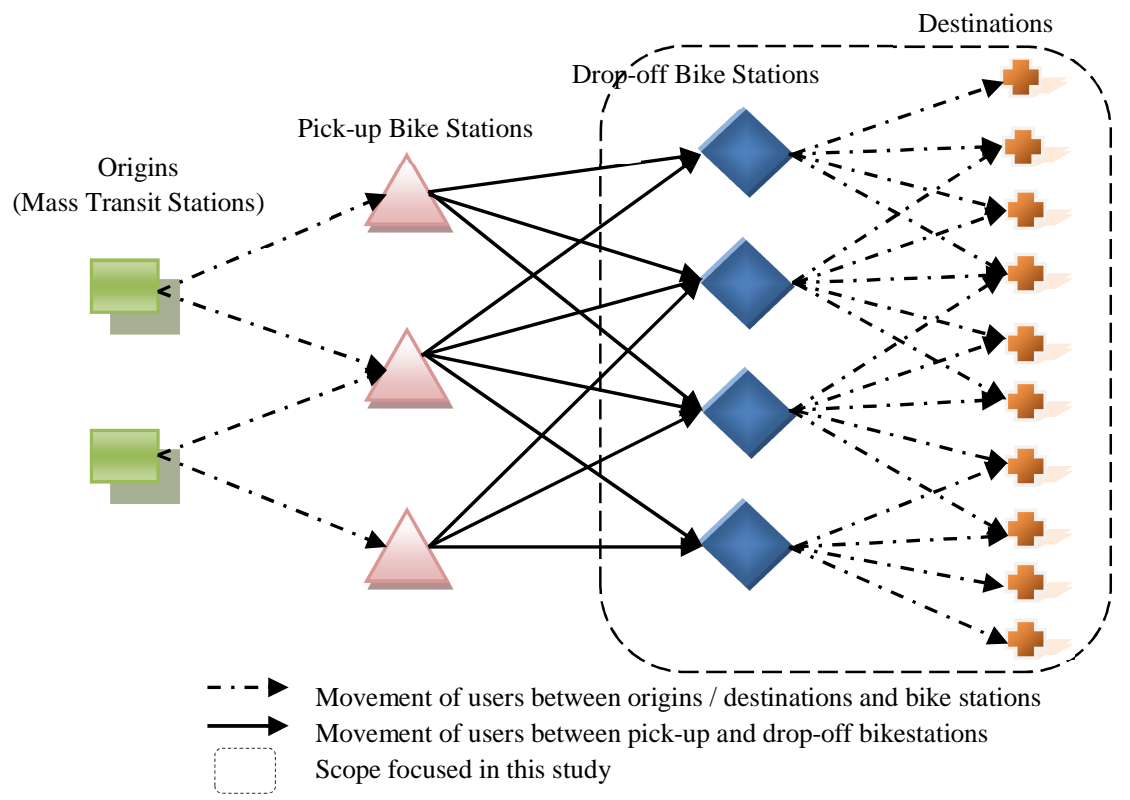

Figure 2. Bike Sharing Network

Source: Adapted from Lin and Yang (2011)

\subsection{Formulation of AHP}

In this study AHP is used to prioritize suitable locations of bike sharing stations in each TAZ. The decision hierarchy was grouped into four objectives, i.e. type of land, amount of available space, accessibility to main bike route, and walkability to destinations. These objectives are explained as follows.

Type of Land: Land which is available for setting up bike sharing stations is classified into two types, i.e. public land and private land (Figure 3). Normally, transport planners prefer to place bike sharing stations on public land. However, in CBD area such as Bangkok where public land is limited, bike sharing stations may be required to be placed on private land. In this case, negotiation with land owners is needed and the project cost increases.

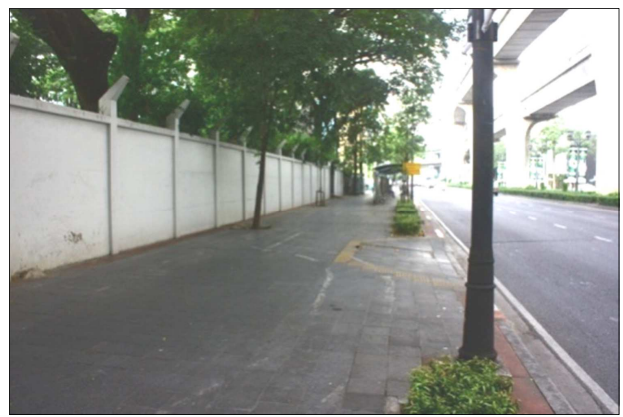

a) Public Land(FootpathArea)

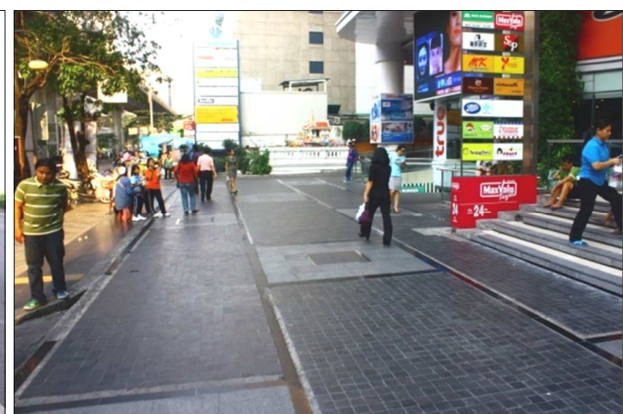

b) Private Land

(Walkway in front of Office Building)

Figure 3. Types of Land for Setting up Bike Sharing Stations 
Amount of Available Space: The bike sharing program by BMA requires minimum space of at least $16 \mathrm{~m}^{2}(2.00 \mathrm{~m}$. wide and $8.00 \mathrm{~m}$. long). In this study the amount of available space of bike sharing stations is classified into 3 categories i.e. fit $\left(16 \mathrm{~m}^{2}\right)$, expandable $\left(16-20 \mathrm{~m}^{2}\right.$, more parking lots can be added in the future), and more than enough (greater than $20 \mathrm{~m}^{2}$ ).

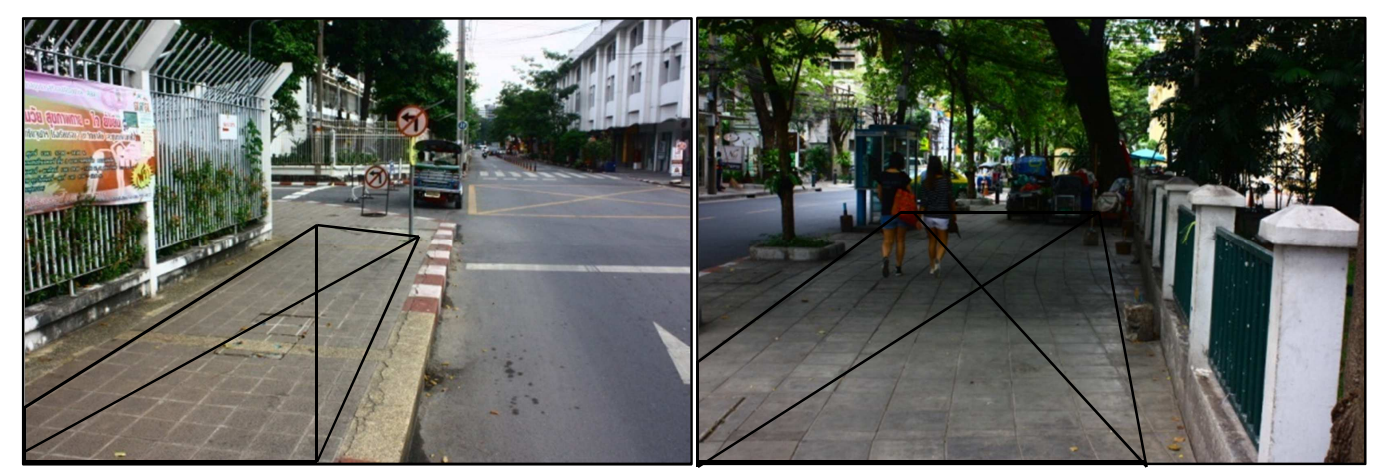

a) Fit $\operatorname{Space}\left(16 \mathrm{~m}^{2}\right)$

b) Expandable Space (16-20 $\left.\mathrm{m}^{2}\right)$

Figure 4. Available Space for Bike Sharing Stations

Accessibility to Main Bike Route: Connection between a potential drop-off station and main bike route (Figure 5) is one of factors considered in prioritizing locations of bike sharing station. The accessibility to bike lane is evaluated by 3 factors: distance between bike station and main bike route, width of bike lane, and riding quality.

- Distances between bike sharing station and main bike routeare classified into 3 classes: close (0$50 \mathrm{~m}$.), moderate $(50-200 \mathrm{~m}$.), and far (greater than $200 \mathrm{~m}$.) from main bike route.

- Widths of bike lanes (right of way) are classified into 3 levels: narrow (less than $3 \mathrm{~m}$.), moderate (3-5 m.), and wide (more than $5 \mathrm{~m}$.).

- Riding qualityon the path connecting bike sharing station and main bike route is reflected bythe quality of road surface and mix of traffic.Pathsare classified into 3 categories: smooth surface \& separated traffic (exclusive right of way), smooth surface \& mixed traffic (shared right of way), and rough surface $\&$ mixed traffic.

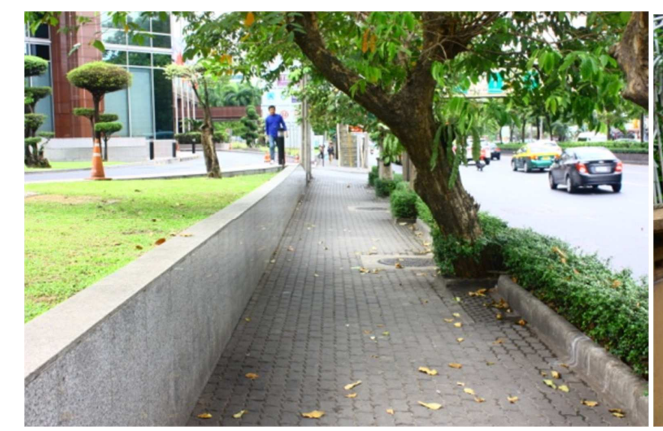

a) Separated Traffic (Exclusive Right of Way)

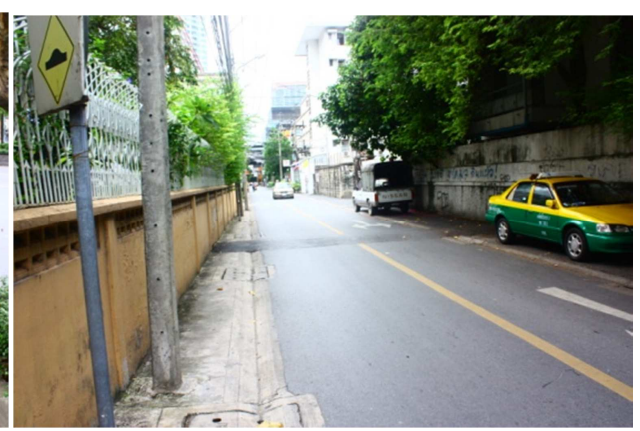

b) Mixed Traffic (Shared Right of Way)

Figure 5. Paths Connecting Main Bike Routes and Bike Stations

Walkability to Destinations: Conditions of pedestrian walkways between drop-off stations and destinations (For example, office building, condominium, shopping center, etc.) reflect the walkability to destinations of the bike sharing system (Figure 6). The "walkability to destinations" consists of subcriteria such as distance between bike station and destinations, width of walkway, and walking conditions. 
Kanjanakorn T., Piantanakulchai M./ Prioritizing Suitable Locations of Bike Sharing Station by Using the Analytic Hierarchy Process (AHP)

- Distances between bike stations and destinations are classified into 3 levels: close $(0-20 \mathrm{~m}$.), moderate (20-50 m.), and far (greater than $50 \mathrm{~m}$.).

- Widths of walkways are classified into 3 levels: narrow (less than $1 \mathrm{~m}$. .), moderate (1-3 m.), and wide (more than $3 \mathrm{~m}$.)

- Walking conditions to destinations are reflected by the quality of walkway's surface (smooth or rough) and presence of obstructions on the walkway such as trees and sign posts.

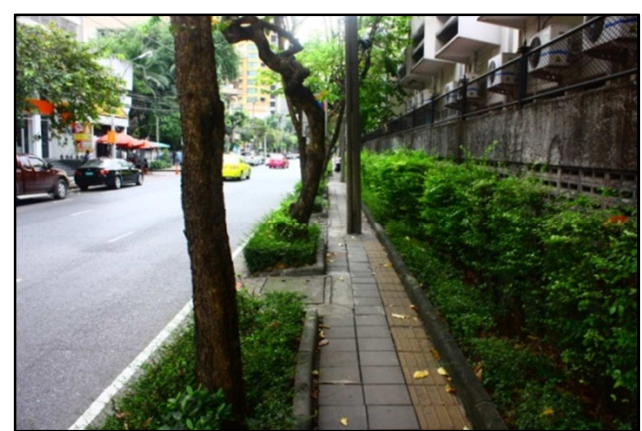

a) Walkway near Silom

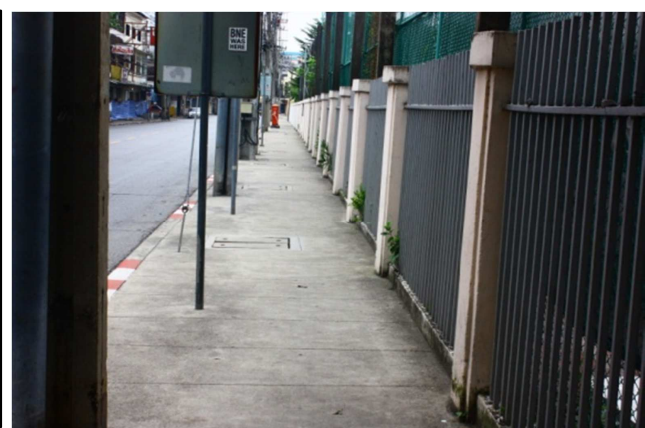

b) Walkway near Siam Square

Figure 6. Conditions of Pedestrian Walkways in Study Area

It is noted that the linguistic definitions factors such as close, moderate, far, narrow, wide, etc. and their associated numerical ranges stated in the previous section were obtained from preliminary survey from BMA experts. The decision making problem in this study is structured by AHP as shown in Figure 7.

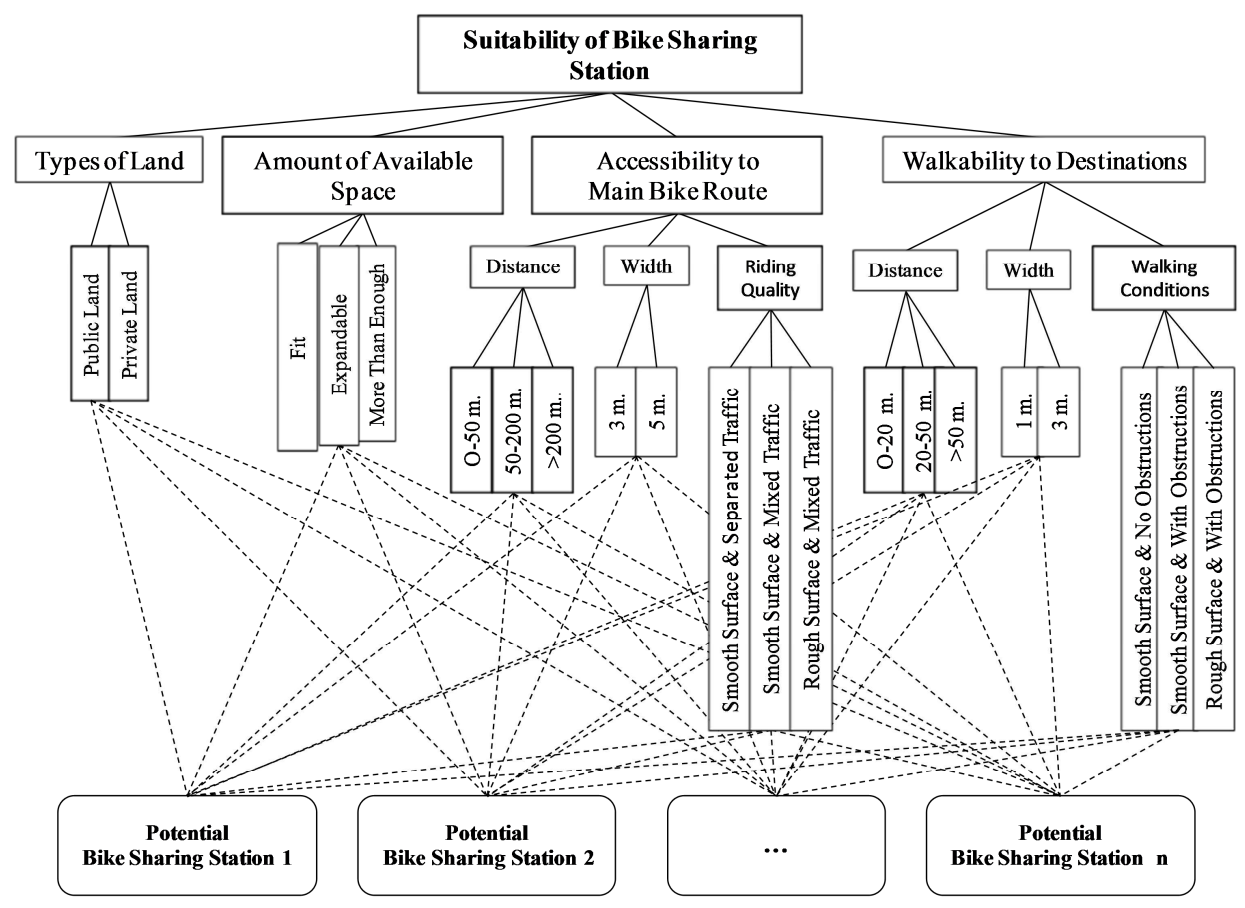

Figure 7. AHP Structure for Prioritizing Suitable Locations of Bike Sharing Station 
The methodology of AHP in this study follows Saaty (1980) and detailed discussion in Piantanakulchai (2005). The Consistency Index (CI) and Consistency Ratio (CR) were used to measure the degree of inconsistency of expert's pairwise comparisons. CR of less than $0.1(10 \%)$ is considered acceptable; otherwise the expert's comparisons will be revised to improve the judgmental consistency. Method of achieving the group's judgment proposed by Saaty (1989) was applied by using the geometric mean method. The method was used to aggregate judgments from experts. Only consistent expert's judgments were included. For the evaluation of judgmental consistency of the group, the Group Consistency Index (GCI) and Group Consistency Ratio (GCR) were calculated. In this study, experts from BMA were asked make pairwise comparisons by using questionnaire and face to face interview. The detail of experts is summarized in Table 1.

Table 1. Summary of BMA Expert's Characteristics

\begin{tabular}{|l|c|c|}
\hline \multicolumn{1}{|c|}{ Position/Job Description } & Number of Experts & Working Experience (Years) \\
\hline Transport Engineers & 3 & $10-15$ \\
\hline Civil Engineers & 6 & $5-8$ \\
\hline Architect & 1 & 10 \\
\hline Head of Planning Section & 1 & 20 \\
\hline
\end{tabular}

\section{Result of Priority Assessment}

The result of study (Figure 8) revealed that the most significant factors concerned by experts in locating bike stations are the accessibility to main bike route $(\mathrm{w}=0.384)$ andthe walkability to destinations $(\mathrm{w}=$ $0.326)$. The amount of available space $(\mathrm{w}=0.180)$ and type of land $(\mathrm{w}=0.112)$ are secondary considerations. All GCR results showed that the combined evaluations by the group of experts were all logically consistent.

Additionally, the results of priorities obtained in the sub-criteria level were plotted with associating factors such as distances, widths, and areas (Figure 9-11). The priorities (weights) are assumed to be linearly dependent with these factors. For "accessibility to main bike route" and "walkability to destinations" as one might expect, the result showed that the more distance to the main bike route or destinations is, the less priority is given to the location. Similar results were found for widths of bike lanes and walkways. The wider bike lanes or walkways are more preferable. For "amount of available space", increase in amount of available space will increase the priority of the location. Furthermore, public land $(\mathrm{w}=0.782)$ is more preferable than private land $(\mathrm{w}=0.218)$. 
Kanjanakorn T., Piantanakulchai M./ Prioritizing Suitable Locations of Bike Sharing Station by Using the Analytic Hierarchy Process (AHP)

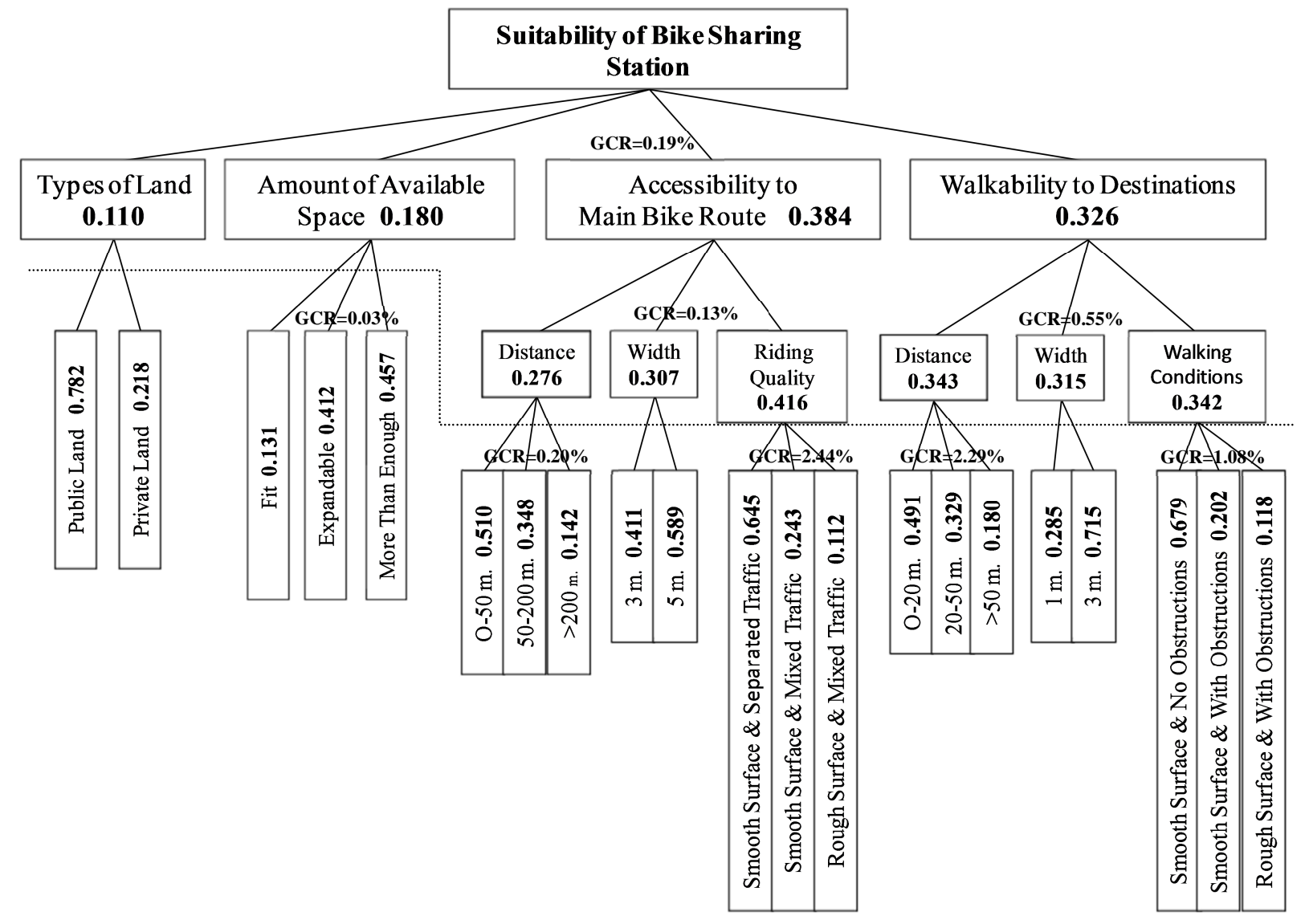

Figure 8. Result of Priority Assessment by BMA Experts

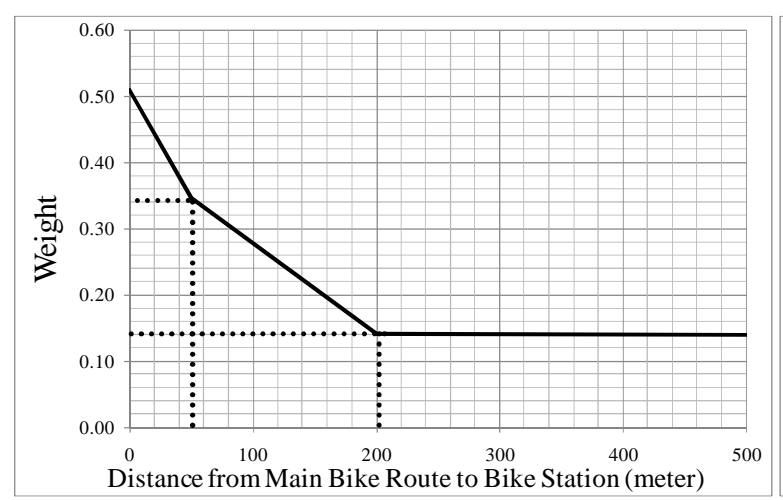

a) Weights by Distance from Main Bike Route to Bike Station

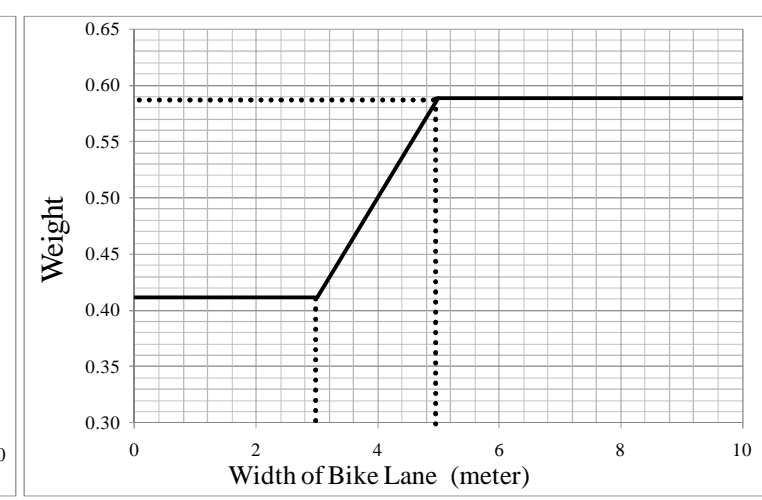

b) Weights by Width of Bike Lane

Figure 9. Priorities for Sub-Criteria of Accessibility to Main Bike Route 


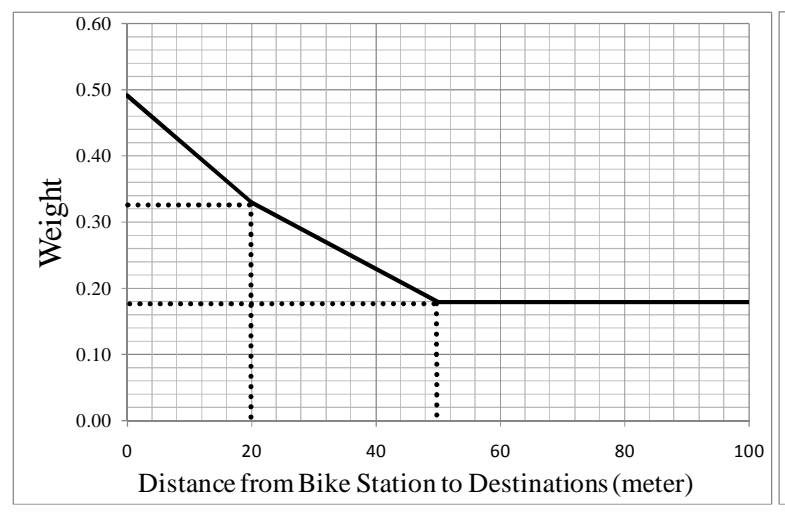

a) Weights by Distance from Bike Station to Destinations

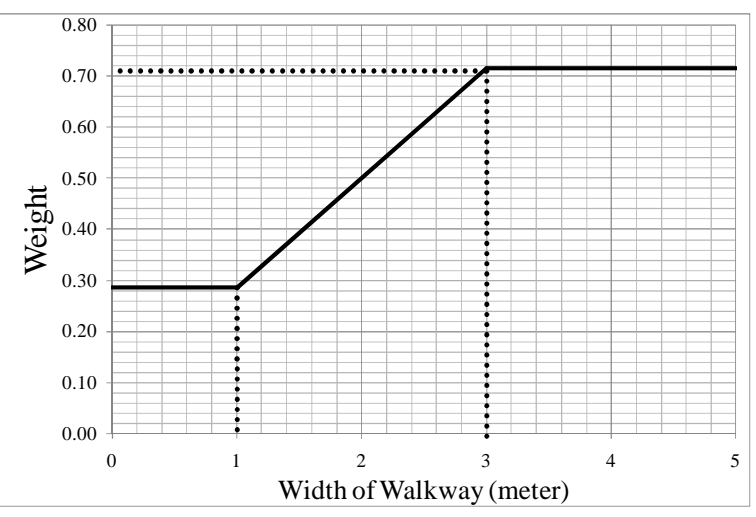

b) Weights by Width of Walkway

Figure 10. Priorities for Sub-Criteria of Walkability to Destinations

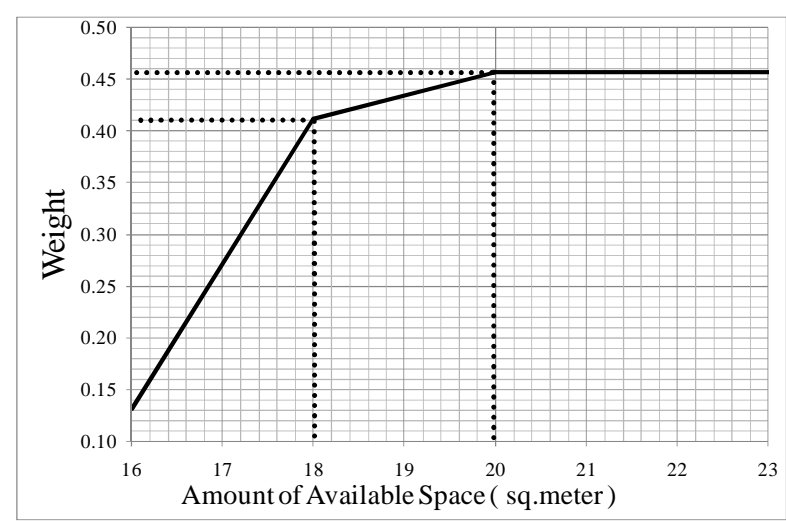

Figure 11. Priorities for Amount of Available Space

The above results (Figure 8-11) were used in the hypothetical case study in order to illustrate the application of the result from AHP.

\section{A Hypothetical Case Study}

An area of $200 \times 200 \mathrm{~m}^{2}$ is used to illustrated the application of AHP in this study (Figure 12). Travel destinations in the study area consist of a department store, an office building, a residential building and a public park. Four potential locations of bike sharing station (A, B, C, and D) are compared using the AHP model developed. Each location is relatively at equal distance away from travel destinations in the zone. In addition, the amount of available space at each location is relatively equal and at least enough to set up a bike station. Characteristics of each candidate for the bike sharing station are given in Table 2. 
Kanjanakorn T., Piantanakulchai M./ Prioritizing Suitable Locations of Bike Sharing Station by Using the Analytic Hierarchy Process (AHP)

Table 2. Characteristics of Candidates for the Best Location of Bike Sharing Station

\begin{tabular}{|c|c|c|c|c|c|c|c|c|}
\hline \multirow[b]{2}{*}{$\begin{array}{l}\text { Potential } \\
\text { Locations }\end{array}$} & \multirow[b]{2}{*}{$\begin{array}{c}\text { Type of } \\
\text { Land }\end{array}$} & \multirow[b]{2}{*}{$\begin{array}{l}\text { Available } \\
\text { Space }\left(\mathrm{m}^{2}\right)\end{array}$} & \multicolumn{3}{|c|}{ Access to Main Bike Route } & \multicolumn{3}{|c|}{ Walkability to Destinations } \\
\hline & & & $\begin{array}{l}\text { Distance } \\
(\mathrm{m} .)\end{array}$ & $\begin{array}{l}\text { Width } \\
\text { (m.) }\end{array}$ & Riding Quality & $\begin{array}{c}\text { Average } \\
\text { Distance } \\
(\mathrm{m} .)\end{array}$ & $\begin{array}{l}\text { Width } \\
(\mathrm{m} .)\end{array}$ & Walking Conditions \\
\hline Location A & Public & 16 & 40 & 8 & Smooth + Mixed Traffic & 85 & 3 & Smooth + Obstructions \\
\hline Location B & Private & 18 & 120 & 8 & Smooth + Mixed Traffic & 80 & 3 & Smooth + Obstructions \\
\hline Location $\mathrm{C}$ & Public & 21 & 125 & 8 & Rough + Mixed Traffic & 50 & 2 & Smooth + Obstructions \\
\hline Location D & Private & 20 & 135 & 8 & Rough + Mixed Traffic & 45 & 2 & Smooth + Obstructions \\
\hline
\end{tabular}

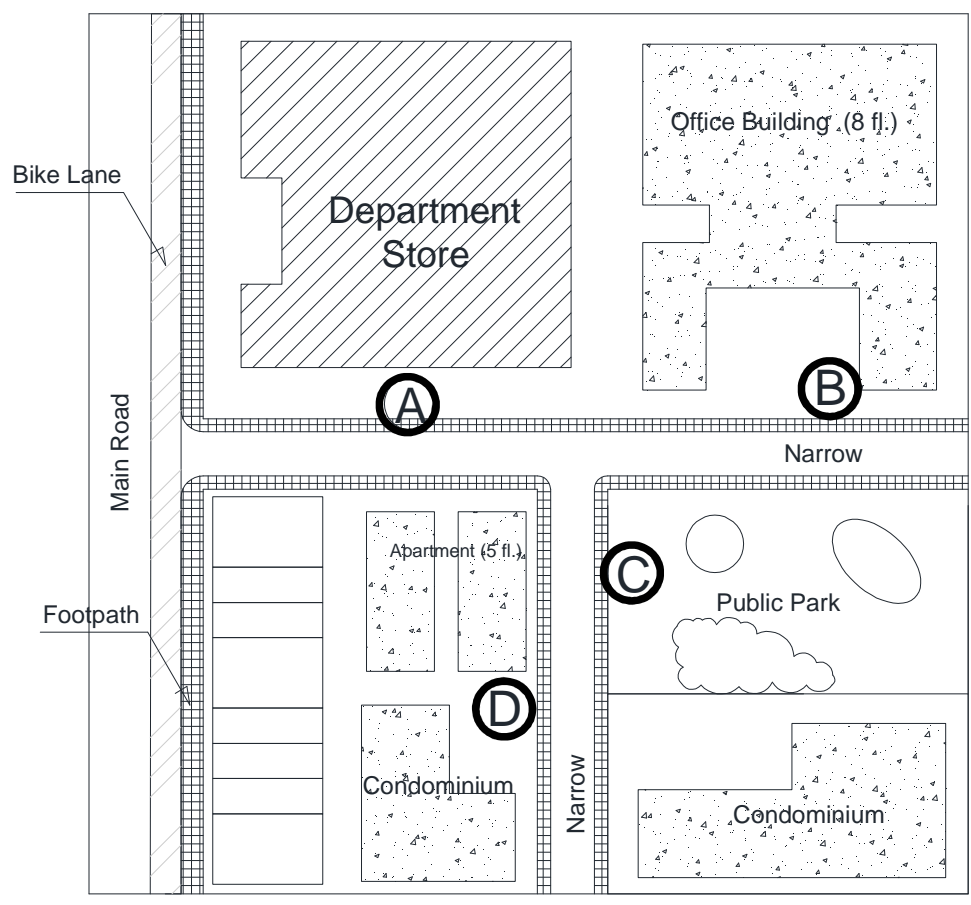

Potential Bike Sharing Stations

Building

Z Department Store

Footpath

Bike Lane

Figure 12.The Study Area in the Hypothetical Case Study

\section{Result of the Hypothetical Case Study and Discussion}

The result of applying AHP to the hypothetical case study (Table 3) showed that location A is the most preferable location for bike sharing station. The preferences are ranked by location $\mathrm{A}, \mathrm{B}, \mathrm{C}$, and D respectively. Location A and B were given higher priorities over location C and D. Unsurprisingly, this is because location A and B provide better access to main bike route and better walkability to destinations. From the result of expert's evaluation, these two factors are the most significant factors concerned in locating bike stations. Moreover, location A is more preferable than location B because it provides better access to main bike route and is public land which is more preferable. Additionally, location $\mathrm{C}$ and $\mathrm{D}$ are similar in most aspects. However, location $\mathrm{C}$ is more preferable since it is public land. 
Table 3. Ranking of Potential Locations for Bike Sharing Stations by AHP Weights

\begin{tabular}{|c|c|c|c|c|c|c|}
\hline \multirow[b]{2}{*}{ Potential Locations } & \multicolumn{4}{|c|}{ Contributions to Total Weight } & \multirow[b]{2}{*}{ Total Weight } & \multirow[b]{2}{*}{ Rank } \\
\hline & Type of Land & Available Space & $\begin{array}{l}\text { Access to Main } \\
\text { Bike Routes }\end{array}$ & $\begin{array}{l}\text { Walkability to } \\
\text { Destinations }\end{array}$ & & \\
\hline Location A & 0.043 & 0.016 & 0.121 & 0.092 & 0.277 & $1^{\mathrm{st}}$ \\
\hline Location B & 0.012 & 0.051 & 0.108 & 0.092 & 0.264 & $2^{\text {nd }}$ \\
\hline Location C & 0.043 & 0.057 & 0.078 & 0.068 & 0.246 & $3^{\text {rd }}$ \\
\hline Location D & 0.012 & 0.057 & 0.077 & 0.073 & 0.218 & $4^{\text {th }}$ \\
\hline
\end{tabular}

\section{Conclusion and Recommendations}

This study presents the application of AHP to rank suitable locations of bike sharing stations. Questionnaires were distributed to experts of Bangkok Metropolitan Administration (BMA) in order to reveal the preferences over specified criteria. The result from AHP group decision making revealed that the most important factors are "accessibility to main bike route", "walkability to destinations", "amount of available space", and "type of land" respectively. A hypothetical case study was used to illustrate the application of AHP. Finally, the developed AHP model is expected to be utilized in practice by BMA for the bike sharing project in Bangkok. However, in this study, it is assumed that implementation costs of alternatives are similar and economy of scale does not exist; therefore, only benefits were compared in AHP. It is recommended for future studies to investigate the effect of including more detailed information regarding cost aspects (user costs, investment costs, economy of scale) into the decision making by using AHP.

\section{REFERENCES}

Lin J.-R. and Yang T.-H. (2011). Strategic design of public bicycle sharing systems with service level constraints. Transportation Research Part E, 47, 284-294.

Piantanakulchai M. and Saengkhao N. (2003). Evaluation of alternatives in transportation planning using multi-stakeholders multi-objectives AHP modeling. Proceedings of the Eastern Asia Society for Transportation Studies. Vol.4, 1613-1628.

Piantanakulchai M. (2005). Analytic Network Process Model for Highway Corridor Planning. Proceedings of the International Symposium on the Analytic Hierarchy Process (ISAHP), July 810, 2005, Hawaii.

Traffic and Transport Department (2011). Bangkok Transportation over the Next Decade. Bangkok Metropolitan Administration, $1^{\text {st }}$ ed. Thailand

Saaty, T.L. (1980). The Analytic Hierarchy Process. McGraw-Hill, New York

Saaty, T.L. (1989). Group Decision making and the AHP. In B. L. Golden, E.A. Wasil, \& P.T Harker (Eds.), The Analytic Hierarchy Process: Applications and Studies. Springer, Berlin 